\title{
Reporting Misdeeds: An Evaluation on Intention to Blowing the Whistle
}

\author{
Nur Zafifa Kamarunzaman, Azlyn Ahmad Zawawi, and Zaliha Hj. Hussin, Member, IACSIT
}

\begin{abstract}
The aims of this study are two folds, to identify whether intention to whistle blow exists; and to ascertain the relationship between perceived organizational support, channel of communication, attitude and intention to blow the whistle. The study was conducted in seven public offices in West Malaysia, involving 511 employees. The findings indicate that all the predicted elements are moderately associated with the act of whistle blowing. On the other hand, channel of communication is proven to be the most dominant variable where the existence of facilities to complaint is seen as the driver for employees to move forward and tell the truth. Moreover internal programs held by the organizations also supported the findings, as a powerful tool to create awareness of the importance to blow the whistle within the organization setting; while fair and just treatments by the organization have generated trust and confidence amongst the employees where they feel empowered and belongingness. Whistle blowing is also perceived as a new commitment by the respondents as reflecting their loyalties to the organization.
\end{abstract}

Index Terms - Whistle blowing, whistle blowing intention, perceived organizational support, channel of communication, Malaysia.

\section{INTRODUCTION}

The introduction of the Wikileaks is a whistle blowing blog which has been made popular by the media depicting how the society concern for the truth. In business setting, many corporations are now gearing up towards establishing their own internal programs to foster whistle blowing, and upgrading their code of conduct in ensuring the clients' feel protected [1]. It is also believed such a noble act could increase the trust of the clientele and indirectly up-lifting the share prices of the company [2]. Off late, disclosure of corporate adverse actions would create attention for many and the stories usually make cover headlines for most countries. Malaysia is not excluded. Since the year 2000, hit stories of illegal and dishonest behavior have served many headlines in the newspaper and high courts. On the other hand, KPMG Forensic Malaysia identify fraud is the major issue in the country [3]. The disclosure of these wrongdoings reflects the increase of public concerns and interest on the subject of whistle blowing.

Malaysian is exposed to the act of whistle blowing initially

Manuscript received July 1, 2013; revised September 5, 2013. This work was supported in part by the Ministry of Higher Education Malaysia under Fundamental Research Grant Scheme.

Nur Zafifa Kamarunzaman and Zaliha Hj. Hussin are with the Universiti Teknologi MARA, Malaysia (e-mail: nurzafifa@kedah.uitm.edu.my, drzaliha@kedah.uitm.edu.my).

Azlyn Ahmad Zawawi is with the Universiti Sains Malaysia, on leave from Universiti Teknologi MARA, Malaysia (e-mail: azlyn@kedah.uitm.edu.my). made for auditors and employees, mostly in big agglomerations. Although many western countries have gauged higher awareness of blowing the whistle, Malaysia was still lacking until the year 2010 in terms of blueprints especially to protect informers. The year 2010 has marked a history for the country where the Whistle Blowing Protection Act was passed by the Parliament. The Act offers wider coverage to the public at large who lodge complaints of the mishaps [4]. Moreover, the Prime Minister has made his commitment on war against corruption by pointing out how transparency could gain public confidence [5].

In spite of the fact that whistle blowing has become the centre of debate and discussion, it is still unknown why some employees who observe wrongdoings report it and some are reluctant to act, or being 'silent observer'. In addition to that, although many cases have been revealed by whistle blowers, it is believed many more are still concealed. The act of stepping up and complaint seems to be a taboo especially in Malaysia since the culture favors 'keeping things to ourselves' and culturally informed notion that it is 'not being our nature to do that' is very strong [6]. What are the determinants for employees to whistle blow? To find the answer to this question, the study aims to discover the elements that relate to individual intention in blowing the whistle in Malaysian context.

\section{Literature ReVIEW AND HyPOTHESIS DEVELOPMENT}

\section{A. Whistle Blowing Intention}

Whistle blowing has become a predominant effort in most organizational setting today. The intention to be good and to do deeds that beneficial to the organization is a noble determinant attempt of employees to ensure both party rights are protected. This new insight of whistle blowing is perceived as many ethical scholars as 'a new commitment' where employees produce their loyalties towards the organization [7]. Robbins and Judge identify one's intention derived from individual attitude which development from the mixture of cognitive and affection that expressed by evaluating an entity with some degree of favor or disfavor [8]. In other words, with instilled values, norms, cultural traits, emotions, and personal experiences, an employee would be able to find as to whether the action that he made is on the right track or elsewhere.

However, whistle blowing is normally not welcome, as some argues that telling the truth will rupture the reputation of a company and trust of the clients [1]. It takes courage to step forward and rectify the adverse action especially when the informer is potential to be retaliated. On the other hand, to whatever extent of retaliation fear which employee faces, the cluster of self belief will be directing one's intention to act 
thus in this case, the same principle is applicable[9]. With these arguments, and the current condition in the population, we suggest that:

H1: There is intention to whistle blow in studied organization

\section{B. Perceived Organizational Support}

At the organizational level, the management support is regard as the main host to encourage employees to whistle blow. Perceived organizational support refers as the extent to which employees seize that organization values their existence and care for their well-being [10]. As highlighted by Levinson, "the personification of an organization can be abetted by the organisation's legal, moral and financial responsibility for the actions of its agents, by organizational policies, norms, and culture that provide continuity and prescribe role behaviours; and by the power the organisation's agent exert over individual employees" [11].

As a simple explanation of the above, employees would feel comfortable, favored or liked with the working environment and treatments which the organization offers. This would be an indication that reflects the organization has given serious attention to the employee needs and wellbeing. In addition to that, it will build confidence and trusts between employee and organization that they are one entity and exist interdependently. For example, an employee is aware that his organization is ready to reward increased work effort and performance; and a state that organization are providing aid when needed in order to carry out task effectively [12].

The other aspects that is strongly associated with perceived organizational support is variety of rewards and favorable working conditions, such developmental experiences which allowing employees to expand their skills, given autonomy in his job territories, visibility to and recognition from the top management [12]. These supports usually would increase employees' certainty towards their supervisor who they perceived as a person who listens to their difficulties and appreciate their efforts. This indirectly opens the door of reporting any observed mishaps in the organization. Since the supervisors are representing the organization and are the ones who evaluating employees and communicating the organizational goals and values to the employees, any kind of treatments by the supervisors are considered as organizational support [12]. Therefore, we suggest that:

H2: Perceived organizational support is positively related to intention to whistle blow

\section{Channel of Communication}

There is basically two medium for whistle blowers, namely the internal and external channel of communication. Some scholars argue that internal channel should not be regarded as whistle blowing while only external can be accounted [13]. In this matter, as they argue, the internal channel involves normal management procedure and reporting wrong behaviors amongst the staff as an integral part of the said system. Staff problems will be undertaken internally and cases usually do not demand high attention. However, we are in the opinion that internal whistle blowing is perceived as one of the important medium because it highlighted the actual behavior of reporting; regardless it involves less serious issues. Moreover, internal medium is regards as 'a precursor to external whistle blowing' when lodged complaints using this tool did not bring any positive result [14]. This stand also supported by Near and Miceli that they define whistle blowing covers internal and external reporting [15]. Simultaneously, Dworkin and Baucus, and Read and Rama state that whistleblowers have a choice whether to whistle blow internally or externally [16] since both of the mediums are literally available in the informers' setting.

On the other hand, disclosing malpractices externally is said to be disastrous compare with internal medium. In many cases, organization favors internal whistle blowing because it could minimize any unintended risk for the company as the problem is not made public [17]. In addition to it, internal channel of communication would help the company to sense the problem before it gets serious and opportunity to deal with the problem domestically [18].

The act of external whistle blowing is an indication that there exist deficiencies in the structure of organization, inadequacy of the communication channels in the organization and failure of management to deal with the whistle blower's complaints. However, the intention to external whistle blowing might be retarded if the organization provides an avenue for hearing and dealing ethical issues internally. Therefore procedures for internal grievance and any complaints of wrongdoings or unethical practices could be investigated and dealt with immediately. With these arguments, we noted that the intention to whistle blow depends on the likelihood of channel of communication availability. We suggest that:

H3: Channel of communication is positively related to intention to whistle blow

\section{Attitude towards Whistle Blowing}

It would be sensible to rely on employees to blow the whistle as they are the ones who have the knowledge about mishaps of their organization but it is not that simple [19]. For example Applebaum cited a study conducted in the United States by the Ethics Resource Center that $44 \%$ of all non-management employees don't report the misconduct they observe for fear of retaliation [19]. Similarly, Rocha and Kleiner state that the potential whistle blower is in a dilemma between what is right and suffering the consequences, or just being quiet and pretending it does not exist [19]. Whistle blowing is a complex issue to address, due to the fact that employees face an extremely difficult choice between their loyalty to the organization on the one hand and their moral and social obligation to do the right thing and face the consequence of blowing the whistle on the other [19].

In another situation, some authors perceive that whistle blowers can actually benefit their employers by offering solutions to work problems. By informing the top management about wrongdoings it gives them a chance to correct the malpractices before the problem escalates. Therefore, instead of posing a challenge to an organizations' authority structure, the disclosure is positively encouraged and employers should provide a channel for reporting. Without a mechanism for employees to raise their concerns, the problems will not be addressed and hence, there is a tendency for the employees to raise the matter externally.

Some writers point out that the motive of disclosing some acts alleged to be malpractices is simply to embarrass a superior or co-worker or to further highlight their own interest. With regard to the above situation, Batson views 
that whistle blowing generally are not always an act of pure altruism. He points out that there often exists "a desire within one organism to increase the welfare of another as an end-state goal" [20]. On the other hand, the act of whistle blowing according to Dozier and Miceli can be viewed as both selfish (egoistic) and unselfish (altruistic) depending on the motives on the part of the actor. If whistle blowers are motivated purely by altruism, and if they act strictly to benefit others then they will report with good intent. If the organization has positive normative and affective buy in by staff then fear of repercussion or retaliation will be minimal. However, if the act is viewed as prosocial behavior according to Staub, then the act of whistle blowing may have more complex motivations in personal advancement as well as ethical commitments. Whistle blowing in this example may be intended to benefit others and the organization but also intended to benefit them by getting rewards [20]. On the other side of the coin, issues of bad perception in telling the truth plays an important role in hindering them to whistle blow, literally in Malaysian culture. The dilemma occurs when the conflict between reporting a friend's adverse action and the culture of not telling bad things about others could hamper one to act. What some staff identifies as perceived unethical activities may not be perceived by others as serious misconduct thus they are unlikely to report on this matter. These points lead to the importance of a shared ethical frame of reference in organizations. However, matters pertaining to obvious illegal conduct would hopefully drive committed staff to blow the whistle [21]. Public servants normally portrayed as acting on motives of duty and the ethical integrity promotes the idea of positive image of public service. Predictors such as low job security and high public interest in public servants can shape a positive attitude to whistle blow. With these arguments, we suggest that:

H4: Attitude towards whistle blowing is positively related to intention to whistle blow

\section{Methodology}

The study was conducted in seven public offices located in West Malaysia, with a total of 1,043 employees. Census sampling technique has been adopted, since we have full access to the offices. This is also in ensuring everyone has a chance to be involved in this study. A self-administered questionnaire was used for data collection. All survey items were used from all validated scales, and the properties of scales were assessed in terms of item consistencies. Literally, the research instruments consist of five sections: Section A Perceived Organizational Support, we adopted and adapted from [21]; Section B - Channel of Communication, from [22]; Section C - Attitudes towards whistle blowing, from [23]; Section D - Whistle blowing intention was adapted from [23]; and final section, Section E - Demographic profiles. Responses were recorded using 6-point Likert-type scales. The data collected were analyzed using Statistical Package for Social Science (SPSS) version 20.0.

The reliability test indicated that the value for Section A, $\alpha$ $=0.795$; Section B, $\alpha=0.787$; Section C, $\alpha=0.939$; and Section $\mathrm{D}, \alpha=0.726$, and the overall reliability of the instruments is $\alpha=0.923$. The summary of the reliability test are as follows:
TABLE I: THE RELIABILITY TEST FOR EACH SECTIONS

\begin{tabular}{lc}
\hline \hline Sections & A \\
\hline Section A & 0.795 \\
Section B & 0.787 \\
Section C & 0.939 \\
Section D & 0.726 \\
Overall & 0.923 \\
\hline \hline
\end{tabular}

\section{RESULT}

The demographic profiles of the respondents will comprise the sex, age, ethnic group, marital status, the level of education and the level of position held in the public offices. The data shows that the woman respondents is higher that the male respondents which participated in the study. The women respondents represent $296(57.9 \%)$ while the male 215 respondents $(42.1 \%)$. For the age cohort, the data indicated majority of the respondents are amongst 20-29 year old (49.9\%); followed by 30-39 year old (33.7\%); 40-49 year old $(11.2 \%) ; 50$ and above represented by 19 respondents 9 $(3.7 \%)$ and 8 respondents $(1.6 \%)$ were below 20 of age. Moreover, the ethnic group has stated that majority of the respondents are amongst Malays, in line with the fact that most of the public positions are filled by this ethnic group. Indian and Chinese were represented by $1.6 \%$ and $.9 \%$ each. In terms of marital status, at least 344 of the respondents $(67.3 \%)$ are married and the other 167 are single/divorcee $(32.7 \%)$. The data also shows that 218 respondents $(42.7 \%)$ are Diploma/ Sijil Tinggi Pelajaran Malaysia (STPM) and 96 are degree/ master holders $(18.8 \%)$, which explained a total of 283 respondents $(55.4 \%)$ holding the executive/ officer post; while 228 respondents $(44.6 \%)$ are at the other level (non-executive) post in these organizations.

The summary of the respondents profile is indicated in the following Table II:

\begin{tabular}{|c|c|c|}
\hline Item & Frequency & Percentage \\
\hline \multicolumn{3}{|l|}{ Sex } \\
\hline Male & 215 & 42.1 \\
\hline Female & 296 & 57.9 \\
\hline \multicolumn{3}{|l|}{ Age } \\
\hline Below 20 & 8 & 1.6 \\
\hline $20-29$ & 255 & 49.9 \\
\hline $30-39$ & 172 & 33.7 \\
\hline $40-49$ & 57 & 11.2 \\
\hline 50-above & 19 & 3.7 \\
\hline \multicolumn{3}{|l|}{ Ethnic } \\
\hline Malay & 495 & 96.9 \\
\hline Chinese & 5 & 1.0 \\
\hline Indian & 9 & 1.8 \\
\hline Others & 2 & 0.4 \\
\hline \multicolumn{3}{|l|}{ Marital status } \\
\hline Single/ Divorcee & 167 & 32.7 \\
\hline Married & 344 & 67.3 \\
\hline \multicolumn{3}{|l|}{ Education Level } \\
\hline$P M R / S P M$ & 128 & 25.0 \\
\hline Certificate & 69 & 13.5 \\
\hline Diploma/ STPM & 218 & 42.7 \\
\hline Degree/ Master & 96 & 18.8 \\
\hline \multicolumn{3}{|l|}{ Position } \\
\hline Executive/ Officer & 283 & 55.4 \\
\hline Others & 228 & 44.6 \\
\hline
\end{tabular}


The mean of the study recorded at the value 4.059 , and the range between items is at 2.711. These values show that there is intention to whistle blowing amongst the respondents and answered the first hypothesis. We identify that respondents have plan to step forward and revealed adverse actions which they witnessed or faced within their organization. The finding supported by [24] where they posit organizations that encourage whistle blowing and support their organizations with proper channels for reporting would embark awareness on whistle blowing act amongst the employees. This is true as the research findings proved most respondents are aware on how to report and whom to report to. Although whistle blowing are not favored by some organizations which it potentially open up more problems in both external and internal environment, but we could see a positive values development of willingness to tell the truth in the studied organization [10]. More often than not, many initial reporting especially within the organization will incline to curb problems before it grows bigger.

For the second hypothesis, we addressed perceived organizational support positively associated with the intention to whistle blow. The respondents have been asked questions such as 'The organization values my contribution to its well-being' and 'The organization cares about my general satisfaction at work'. The result reveal that there is moderate correlation established where $r=0.379(p<0.05)$. Hence the second hypothesis is accepted. Perceived organizational support is regard as to what extent the company supports the wellbeing of each worker which they feel needed, appreciated and protected by the organization. It is a form of employer-employee relation predicted by many result favorable outcomes through fair treatment. It can be said that when an employee are well treated, he will be more committed at his work [12]. It is believed that organizational support has to some degree determined the intention to blow the whistle amongst employees, especially when they trust and feel safe with just treatments given by accountable supervisor [25]-[28]. Gaines for example observed that individual who trust their supervisor posses upward communication of problems than do other members in organization [29]. Simultaneously, Blackburn, Graham, Miceli and Near posit that when an individual have firm believe on his supervisor, it increased perceived benefits of reporting relative to the perceived costs [30]-[32]. Put it simply, when trust has been established, an employee tend to report mishaps which he faced or observed without hesitate or threaten by the reprisal by other party. This in turn increases the benefit-to-cost differential, increasing the likelihood of whistle blowing [33].

The third hypothesis was addressed to identify whether there is positive relationship between the channel of communication and the intention to whistle blow. The analysis discovered that there is positive relationship between the variables, where $r=0.436$ ( $p<0.05)$. The finding indicates majority of respondents are likely to commit with internal channel of reporting than external. Sample questions which been asked are, 'There is a system to identify colleagues or supervisors with whom I can share my concerns regarding misconducts or undesirable behavior', and 'Organizational environment and the nature of work allow effective whistleblowing practices in my workplace...' The essence of confidentiality and trust must exist to encourage whistle blowing internally although they might turn to external resources, especially when the internal channel failed to result any action from the management [17]. While the literatures noted that external whistle blowing is giving more damage compared to internal reporting, this situation proved that many employees confident with the organizational channel of communication such as channeling their complaints to their immediate supervisors. Whistle blowing through internal channel is considered as a type of internal communication which can minimize any unintended risk to the organization [17]. In addition, internal whistle blowing will allow organization to deal with the matter domestically before it can be made public [18]. On the other hand, a positive outcome of the most recent passed Act, the Whistle blowing Protection Act (2010) and the war against corruptions committed by the Prime Minister can be validated by the result of this study. It is good to know various channels established to support this effort and it existed with protection for public at large. It is important that an individual's identity be concealed away from the public to avoid future retaliation.

Simultaneously, forth hypothesis tries to recognize the relationship between employee attitudes and whistle blowing intention. The sample of questions asked were testing the respondents to what extent their belief of reporting adverse actions within the organizational setting. Some example of the questions are 'Blowing the whistle would help prevent serious harm to an organization', and 'Reporting wrongdoing in the workplace is a way for an employee to do his or her duty'. The result states that there exist moderate relationship between employees' attitude and intention to whistle blowing, where $r=0.362 \quad(p<0.05)$. With the presentation of the result, we conclude that knowledge and awareness are seen to be the impetus of whistle blowing attitude in any man. The more an employee equip with information, knowing ways how to and to whom to report to, they likely to be ready to step into the reporting chamber [2]. On the other hand, company's program addressing the vitality of whistle blowing would drive employees to be more confident in executing their duty to the organization. Perpetuating this morally act should be undertaken to socialize and further acculturate the values in the office environment. This effort has synergies with moral philosophy which earmarked by Emanuel Kant, in his Kantian 'social contract' that he derived from 'reconciliation between authority and autonomy' [34]. In other words, an employee should be enlightened in regards to his rights to whistle blow. Organization should prepare a ground to make employees understand the company's code of ethics, and other procedures that bind them in the employment. With the knowledge, awareness can be created and employees tend to be open to report mishaps as they realized the significant to do so, for the sake of the organization and themselves.

The data were further tested with multiple regression and we discovered that the most influential factor to gauge the intention of whistle blowing amongst the respondents are availability of channel of communication $\left(R^{2}=0.216\right.$, $p<0.05)$; followed by perceived organizational support $\left(R^{2}\right.$ $=0.174, p<0.05)$; and one's attitude towards this morally act $\left(R^{2}=0.101, p>0.05\right)$. As argued before, availability of 
channel of communication reflects the organization seriousness and government to combat mishaps as at organizational and societal level. In this case, awareness on the availability of channel are existed and many of these respondents nominated the preferences of using internal than external channel to report wrongdoings. This is consistent with who wrote that Malaysian societal norms inclined to 'keep things to ourselves' rather than disclosing others' wrongdoings publicly. In order to deter such 'unhealthy' behavior, he suggests for Malaysian to open up self to new norms and work towards this morally act. Besides, our findings prominently postulate that organizations should undertake their roles seriously in nurturing employees not only rules and regulations, but instilling good values within the office environment though organizational culture. For instance, employees are dependable to the employer most of the time and the space created cleavages of opportunity for organizations generate trust within the context [6]. Moreover, the results posit that openness to whistle blowing culture is actually making its way amongst the public servants. At this level, we suggest more organizational programs to be organized.

\section{CONCLUSION}

In a nutshell, blowing the whistle is not something that easy to commit. The effort to create the awareness on this and immerse it into daily life culture is important to ensure sustainability of the act and generation of honest society can be created. The Malaysian Whistle Blowing Protection Act (2010) has given its society a platform to exercise their obligation to tell the truth of what they have witnessed or come into their knowledge. Since the passed Act, many Malaysian agglomerates and public offices have provided internal program in giving encouragement to the employees to whistle blow and proved honesty could improvise productivity.

The results lead us to a point where whistle blowing is making its way in Malaysia. The findings indicate the intention to blow the whistle has been established amongst the public servants particularly in West Malaysia, where the effort by the employer could not be denied. The effort such as giving rooms for complaints and treating the problem as exclusive and takes action of the said problems, have eventually built confidence and empowered the employees. At the same time, we foresee the role of the supervisor as for the first line of management level which closer to the employees in terms of the daily routine, able to create feeling of belongingness in them. Should such qualities established, the organization can ensure that external whistle blowing is far from possible. More often than not, organizational support such as effective dissemination of information through internal programs is perceived as one of the powerful tool for socialization between employees with the organization's code of ethics. In materializing this effort, the organization should have a platform to expose the employees with the reality of harms for adverse action to the organization and the association with the employees' yearly reward, such as bonuses, promotions and others. The awareness could foster the act of whistle blowing. The literature suggested the organization should have mechanisms to protect the whistle blowers from retaliation. This is vital to be addressed as confidentiality must be put as a priority in handling reported cases. In this paper, we confirm our conceptual framework that channel of communication, attitude of public servants, and perceived organizational behavior are related to the intention to whistle blowing in studied organizations.

\section{ACKNOWLEDGMENT}

We would like to thank the Ministry of Higher Education Malaysia who has given us financial support to execute this study under the fund of 'Fundamental Research Grant Scheme'. We also would like to extend our appreciation to our university, Universiti Teknologi MARA for its technical support and make this research possible.

\section{REFERENCES}

[1] R. M. Bowen, A. C. Call, and S. Rajgopal, "Whistle-blowing: target firm characteristics and economic consequences," The Accounting Review, vol. 85, no. 4, pp. 1239-1271, 2010.

[2] G. Vinten, "Towards a theology of whistleblowing," Theology, vol. C, no. 794, pp. 90-100, 1997.

[3] KPMG Malaysia fraud survey report 2009, Petaling Jaya, Selangor: KPMG Forensic Malaysia, 2009.

[4] A. Kadir. (2010). Whistle blowing's credible governance. New Straits Times. [Online]. Available: http://www.nst.com/nst/articles/20deept/Article/

[5] Whistle blower policy set to be used in more agencies. The Star. [Online]. Available: http://www.thestar.com.my

[6] D. Lehmann. (July 2010). Whistleblowing won't work in Malaysia. [Online]. Available: http://www.deloitte.com/view/en_MY/my/myii/2e375ecf32fd5210Vg nVCM200000bb42f))aRCRD.htm

[7] J. R. M. Magnus and C. Viswesvaran, "Whistleblowing in organization: an examination of correlates of whistleblowing intentions, actions, and retaliation," Journal Business Ethics, vol. 6, pp. 277-297, 2005.

[8] S. P. Robbins and T. A. Judge, Organizational Behavior, $12^{\text {th }}$ ed. Upper Sadle River, New Jersey: Prentice Hall, 2004.

[9] L. E. Miller and J. E. Grush, "Improving predictions in expectancy theory research: effects of personality, expectancies, and norms," Academy of Management Journal, vol. 31, no. 1, pp. 107-122, 1988.

[10] H. Levinson, "Reciprocation: The relationship between man and organization,” Administrative Science Quarterly, vol. 9, pp. 370-390, 1965.

[11] J. Aselage and R. Eisenberger, "Perceived organizational support and psychological contracts: A theoretical integration," Journal of Organizational Behavior, vol. 24, no. 5, pp. 491-509, 2003.

[12] J. P. Meyer and N. Alen, "Testing the "side-bet theory" of organizational commitment: some methodological considerations," Journal of applied Psychology, vol. 69, pp. 372-378, 1984.

[13] W. J. Read and D. V. Rama, "Whistle blowing to external auditors", Managerial Auditing Journal, vol. 18, no. 5, pp. 354-362, 2003.

[14] N. Brennan and J. Kelly, "A study of whistle blower among trainee auditors," The British Accounting Review, vol. 39, no. 1, pp. 61-87, 2007.

[15] T. M. Dworkin and M. S. Baucus, "Internal vs. external whistleblowers: a comparison of whistle lowering processes," Journal of Business Ethics, vol. 17, pp. 1281-1298, 1998.

[16] M. J. Somers and J. C. Casal, "Organizational commitment and whistle-blowing: A test of the reformer and the organization man hypotheses," Group and Organization Management, vol. 19, pp. 270-284, 1994.

[17] S. A. Ahmad, "Internal auditors and internal whistle blowing intentions: a study of organizational, individual, situational and demographic factors," PhD Thesis, Edith Cowan University Western Australia, 2011.

[18] G. Liyanarachchi and C. Newdick, "The impact of moral reasoning and retaliation on whistle-blowing: New Zealand evidence," Journal of business ethics, vol. 89, pp. 31-57, 2008.

[19] J. B. Dozier and M. P. Miceli, "Potential predictors of whistle-blowing A prosocial behavior perspective," Academy of Management Review, 1985. 
[20] E. S. Callahan and J. W. Collins, Employee attitudes toward whistleblowing: management and public policy implications, Journal of Business Ethics, vol. 11, pp. 939-948, 1992.

[21] R. Eisenberger, R. Huntington, S. Hutchison, and D. Sowa, "Perceived organizational support", Journal of Applied Psychology, vol. 71, pp. 500-507, 1986.

[22] T. J. Yuen and M. S. Majid, "Knowledge sharing patterns of undergraduate students in Singapore," Emerald Library Review, vol 56 no. 6, pp. 485-494, 2007.

[23] H. Park and J. Bienkinsopp, "Whistle blowing as planned behaviour: A survey of South Korean Police Officers," Journal of Business Ethics, vol. 85, pp. 545-556, 2009.

[24] M. P. Miceli and P. N. Near, "Individual and situational correlates of whistle blowing," Personnel Psychology, pp. 267-268, 1988.

[25] G. Mellinger, "Interpersonal trust as a factor in communication," The Journal of Abnormal and Social Psychology, vol. 52, no. 3, pp. 304-309, 1956

[26] W. H. Read, "Upward communication in industrial hierarchies," Human Relation, vol. 15, no. 1, pp. 3-15, 1962.

[27] K. H. Roberts and C. A. O'Reilly, "Measuring organizational communication," Journal of Applied Psychology, vol. 5, no. 3, pp. 321-326, 1974.

[28] L. T. Hosmer, "Trust: The connecting link between organizational theory and philosophical ethics," Academy of Management Review, vol 20, no. 2, pp. 379-403, 1995

[29] A. D. Gaines, "Cultural definitions, behaviour and the person in American Psychiatry," in Conceptions of mental health therapy, A. Marcella and G. White, Eds. Dordrecht: D. Reidel, 1982.

[30] S. Blackburn, "Attitudes and contents," Ethics, vol. 98, no. 3, pp. 501-517, 1988.

[31] H. Graham, The human face of psychology: Humanistic psychology in its historical, social, and cultural context, Open University Press, 1986.

[32] T. M. Dworkin and J. P. Near, "A better statutory approach to whistle blowing," Business Ethics Quarterly, vol. 7, pp. 1-16, 1997.

[33] M. Keil, A. Tiwana, R. Sainsbury, and S. Sneha, "Towards theory of whistle blowing intentions: a benefit to cost differential perspective," Decision Science, vol. 41, 2010.

[34] E. E. Tsahuridu and W. Vandekerckhove, "Organisational whistleblowing policies: making employees responsible or liable?" Journal of Business Ethics, vol. 82, pp. 107-118, 2007.

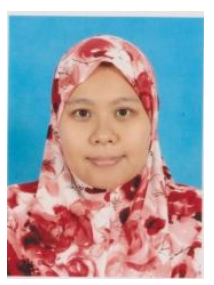

Nur Zafifa Kamarunzaman was born in Kuala Lumpur Malaysia on $7^{\text {th }}$ February 1979. She gained her early education in Klang, Selangor and further her tertiary education in Bachelor Science (Human Development) (1999-2001) from Universiti Putra Malaysia and Master in Social Science (Antropology \& Sociology) from University Kebangsaan Malaysia (2004-2006). She will be soon being a PhD candidate in Universiti Sains Malaysia. Her research interest is in the area of Community Development, specializing civil society movement. She is currently working as a Lecturer in Universiti Teknologi MARA, Malaysia since 2007 till present. She has previously served Puncak Niaga Holdings which based in Kuala Lumpur and Carrefore (Magnificient Diagraph Sdn.
Bhd. as Human Resources Executive. She has produced a writing manual titled, 'Buku Panduan Penulisan untuk JSPPP' (Kuala Lumpur: UiTM Press), and contributed several chapters in book, some of the title of the articles are 'Kedudukan Orang Melayu Sebagai Golongan Minoriti Di Singapura, in Hubungan Etnik di Malaysia' (Kuala Lumpur, UPENA, 2008), and 'Ilmu Kolonial Dan Pembentukan Malaysia: Analisa Ringkas Kesan Ke Atas Sistem Dan Struktur Negara' (Kuala Lumpur, DBP, 2011). Her current works involve two funded projects from the Ministry of Higher Education of Malaysia entitled 'The Relationship between Followers' Typology, Conformity and Organizational Citizenship Behavior' and 'Whistle Blowing Anti-Retaliation Precautionary Measures Model'. Nur Zafifa Kamarunzaman is a member of International Economics Development Research Center (IEDRC) and Malaysian Social Science Association (PSSM).

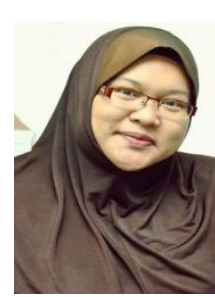

Azlyn Ahmad Zawawi was born November $30^{\text {th }}, 1981$ from Perak, Malaysia, holds a bachelor's degree from Universiti Teknologi MARA Malaysia majoring in Corporate Administration (2002-2004). She then pursued her Masters of Art with Industrial and Organizational Psychology in major (2005-2007). Currently, she is in her PhD candidature at Universiti Sains Malaysia, in the field of Human Resource Management specializing in Team Performance Management. She works as an Academician in Universiti Teknologi MARA Malaysia since year 2007 till present. Previously, she served The Royal Mint of Malaysia (located in Shah Alam, Malaysia) as a Human Resource Executive (2004-2005). Her current research works include two funded projects from the Ministry of Higher Education of Malaysia entitled 'The Relationship between Followers' Typology, Conformity and Organizational Citizenship Behavior' and 'Whistle Blowing Anti-Retaliation Precautionary Measures Model'. She has presented in numerous conferences and research seminars including the most recently 2012 IEEE Symposium on Business, Engineering and Industrial Applications (ISBEIA 2012) held in Bandung, Indonesia and 10th Asean Academy of Management Conference 2013 (AAMC 2013) held in Batu Feringghi, Penang, Malaysia. Azlyn Ahmad Zawawi is a member of Asean Academy of Management and International Economics Development Research Center (IEDRC). Her areas of interest for research works include organizational development, industrial psychology and human resource management.

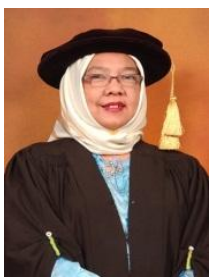

Zaliha Hj. Hussin was born in Johor Bahru, Malaysia on Mei $20^{\text {th }}$, 1953. Her tertiary education starts from Bachelor of Arts (Antropology \& Sociology) from University of Malaya, Malaysia; Master of Arts from Liverpool University; and Doctor of Philosophy from University of York specializing in employee's security. Currently, she is working with Universiti Teknologi MARA as the Dean of the Faculty of Administrative Science \& Policy Studies (January 2013 till to-date). Previously she had served Universiti Teknologi MARA, Kedah branch as the Rector for almost eight years, from 2003 to 2011. Professor Dr. Zaliha Hj. Hussin's research interest includes organizational behavior, local government, and human resources management. 